\title{
Tourism, Health and Income in Malaysia
}

\author{
Cheah Chan-Fatt ${ }^{1}$, A.S. Abdul-Rahim ${ }^{2}$ \\ ${ }^{1,2}$ Department of Economics, Faculty of Economics and Management, Universiti Putra Malaysia, \\ 43400 Serdang, Selangor, Malaysia.
}

\begin{abstract}
This study employed the ARDL bounds test and Granger causality test to investigate long- and the short-run relationships among economic development, tourism sector development, and health care sector development in Malaysia. Annual time series data from 1981-2011 also were employed in this study. Based on our tests, there is a long-run relationship from economic development to health care sector development and from tourism development to health care sector development..
\end{abstract}

\section{Introduction}

In the past five years, Malaysia has become a health tourism destination for tourists around the world. According to the Malaysia Healthcare Travel Council [1], the total of health care travellers had increased 49.2\% from 2007 to 2012. Malaysia also received positive feedback from patients who had gone to Malaysia for health care services.

On the other hand, Malaysia also shows an increase in economic development via an increase in the Malaysian gross domestic product (GDP). As income increases for the Malaysians, health care spending also is increased. Malaysia citizens have spent about RM 31.6 billion on health care services during 2011.

Next, the percentage of total tourist receipts to total GDP of Malaysia at year 2012 is about $6.5 \%$. This means that the tourism sector had a significant impact on Malaysia's economic development. Based on the above evidence, we can say there were relationships among economic development, tourism sector development, and health care sector development.

According to the Malaysia Healthcare Travel Council [2], there are three reasons why Malaysia can be an ideal destination for tourists who are looking health care services from abroad: 1) value for tourist money; 2) multicultured society and great hospitality; and 3) holiday advantages.

By definition, health tourism or medical tourism means that patients travel abroad to other countries to look for health care services $[3,4,5,6]$. Most patients from developed countries look for health care services from developing countries because it is cheaper to reduce waiting time and for health care services not offered in the home country [3,6]. Medical tourism is the emergence of a new term, which is sometimes differentiated with health tourism and sometimes not [7]. However, in this study, both terms apply to the same category of tourism.

According to Hundt [8], the tourism sector is the fastest-growing sector around the world, and it will generate income to a country. But, according to Outreville [9], the health care sector grew fast in developing countries during the past with help from foreign direct investment (FDI). FDI is an important tool in increasing a country's GDP for most developing countries around the world. 
Durbarry [10] found that a $1 \%$ increase of the tourism sector will lead to an $0.8 \%$ economic growth in Mauritius. Most developing countries will gain from the tourism sector an increase in the country's GDP. Export of a country also will improve the country's GDP growth through research and development (R\&D) and training of human capital [10].

Based on Lee and Hung [11], they found a long-run relationship between the health and tourism sectors to Singapore's GDP; a short-run relationship from GDP and tourism sector to Singapore's health sector and from health sector to Singapore's tourism sector. From here, it shows that the health and tourism sectors contribute to Singapore's GDP in the long run. Hard work had done by the Singapore government to promote itself as a leading medical hub to attract more tourists to go Singapore for health tourism [11].

On the other hand, Tang [12] found a long-run relationship from real income and real exchange rates to Malaysian real tourism receipts; long-run relationship from real tourism receipts and real exchange rates to Malaysian real income; short-run relationship from real exchange rates to Malaysian real income and real tourism receipts. Tang [12] also highlighted that the exchange rates is an important factor for international tourists to decide their destination for tourism.

Owing to the emerging health tourism in Malaysia, we have to understand the active role played by Malaysia in the development of its health tourism. Malaysia provides a good basis for this kind of study. For example, Malaysia has achieved a good population health status with low health care spending [13]. We could say that Malaysia serves as role models for other developing economies, as it has achieved rapid economic growth in the last 50 years. By experiencing in health care reforms, this becomes an important contribution to global policy discussion on trade in health services as a push factor for a country's economic development.

Hence, it is important to find out the relationship among a country's GDP, health, and tourism. By doing so, it will help policy makers boost the country's economic growth. The Granger causality test is useful to find out the long- and short-run relationships among them. Results of the Granger causality test indicate policy makers will work out the action plans accordingly.

\section{Data, Methodology, and Results}

Annual time series data from 1981-2011 were employed in this study. The data of real income per capita $(G D P)$ were employed as a proxy of the development for the Malaysia economic sector; real health expenditure by government per capita $(H E A L T H)$ as a proxy for the Malaysia health care sector development; and the total tourist arrivals to Malaysia (TOURISM) as a proxy of the Malaysian tourism sector development.

The data for GDP, consumer price index (CPI), and total population of Malaysia are obtained from world development indicators, such as the World Bank (2013); total government health expenses are obtained from the Ministry of Finance Malaysia (2013); and total tourist arrivals are obtained from the Ministry of Tourism Malaysia (2013).

To test the cointegration between variables in this study, an ADF test, PP test, bounds test, and Granger causality test have been employed to discover integration for each variable, the cointegration of the variables in the long and short runs and the Ganger causality effect in long- and short-run relationship between the variables.

Before starting the bounds test, it was important to find out the orders of integration for each variable by employing an augmented Dickey-Fuller (ADF) test and Phillips and Perron (PP) test [10, $11,12]$. The ADF and PP tests have been employed to identify the orders of integration of each variable. If the variable is stationary at level, it means that it is $\mathrm{I}(0)$; if the variable is stationary at the first difference, it means it is I(1). Each variable had been tested with intercepts and time trends for the level and first difference. 
Table 1. Results of ADF and PP Tests

\begin{tabular}{|c|c|c|c|c|c|c|c|c|}
\hline \multicolumn{5}{|c|}{ Level } & \multicolumn{4}{|c|}{ First Difference } \\
\hline & $\mathrm{ADF}$ & & PP & & $\mathrm{ADF}$ & & PP & \\
\hline$G D P$ & $-2.8571[0]$ & & $-2.7631(4)$ & & $-5.1835[0]$ & $* *$ & $-5.2382(4)$ & $* *$ \\
\hline HEALTH & $-4.9960[0]$ & $* *$ & $-4.9846(2)$ & $* *$ & $-8.4544[0]$ & $* *$ & $-27.1164(26)$ & $* *$ \\
\hline TOURISM & $-2.8931[0]$ & & $-2.7386(5)$ & & $-5.3060[0]$ & $* *$ & $-8.7721(21)$ & $* *$ \\
\hline
\end{tabular}

Note: ADF and PP tests critical values are based on MacKinnon (1996) one-sided p-values. ADF tests for lag length section [...] are based on Schwarz information criteria, which are shown in the bracket; and PP tests for lag length section (...) are based on Bartlett kernel. ** Significant at 5\% level.

Based on the results of the ADF and PP tests in Table 1, only HEALTH is significant at level and rejects $H_{0}$ by concluding it is stationary at level. But for GDP and TOURISM, there is a significant first difference and rejects $H_{0}$ by concluding that it is stationary at the first difference level. It means that HEALTH is I(0); GDP and TOURISM are I(1).

Next, the bounds test was employed to discover the long-run relationship between the variables. Bounds testing was employed because it can find the cointegration of all variables that were tested without caring that the variables are $\mathrm{I}(0), \mathrm{I}(1)$, or mutually cointegrated [14]. The bounds test has been employed to find out the long-run relationship with the following unrestricted error-correction models:

$$
\begin{aligned}
& \Delta G D P_{t}=a_{0}+\sum_{i=1}^{q} a_{G i} \Delta G D P_{t-i}+\sum_{i=0}^{q} a_{T i} \Delta \text { TOURISM }_{t-i}+\sum_{i=0}^{q} a_{H i} \Delta H E A L T H_{t-i}+a_{1} G D P_{t-1} \\
& +a_{2} \text { TOURISM }_{\mathrm{t}-1}+a_{3} \text { HEALTH }_{\mathrm{t}-1}+\varepsilon_{1 \mathrm{t}} \\
& \text { DTOURISM } \text { TO }_{\mathrm{t}}=b_{0}+\sum_{i=1}^{q} b_{T i} \Delta \text { TOURISM }_{\mathrm{t}-\mathrm{i}}+\sum_{\mathrm{i}=0}^{q} b_{G \mathrm{i}} \Delta G D P_{\mathrm{t}-\mathrm{i}}+\sum_{\mathrm{i}=0}^{q} b_{\text {Hi }} \Delta \text { HEALTH }_{\mathrm{t}-\mathrm{i}}+b_{1} G D P_{\mathrm{t}-} \\
& +b_{2} \text { TOURISM }_{\mathrm{t}-1}+b_{3} \text { HEALTH }_{\mathrm{t}-1}+\mathrm{e}_{2 \mathrm{t}} \\
& \Delta H E A L T H_{\mathrm{t}}=c_{0}+\sum_{\mathrm{i}=1}^{q} c_{H \mathrm{i}} \Delta H E A L T H_{\mathrm{t}-\mathrm{i}}+\sum_{\mathrm{i}=0}^{\mathrm{q}} c_{G \mathrm{i}} \Delta G D P_{\mathrm{t}-\mathrm{i}}+\sum_{\mathrm{i}=0}^{\mathrm{q}} c_{T \mathrm{i}} \Delta \text { TOURISM }_{\mathrm{t}-\mathrm{i}}+c_{1} G D P_{\mathrm{t}-1} \\
& +c_{2} \text { TOURISM }_{\mathrm{t}-1}+c_{3} \text { HEALTH }_{\mathrm{t}-1}+\varepsilon_{3 \mathrm{t}}
\end{aligned}
$$

The values of $q$ for Equations (1), (2), and (3) start from 1 and are increased until they meet the null hypothesis of no autocorrelation by using the Breusch-Godfrey Lagrande multiplier test up to lag order 2 at $5 \%$ significance level. Results of the bounds test and null hypothesis are shown in Table 2.

Table 2. Results of Bounds Test for Cointegration

\begin{tabular}{ccc}
\hline Equation & $H_{0}$ & F-value \\
\hline$(1)$ & $a_{1}=a_{2}=a_{3}=0$ & 1.4491 \\
$(2)$ & $b_{1}=b_{2}=b_{3}=0$ & 0.6364 \\
$(3)$ & $c_{1}=c_{2}=c_{3}=0$ & $4.3625 *$ \\
\hline
\end{tabular}

* Significant at 10\% level

According to Pesaran et al. [14] in Table CI (iii), the critical values of the bounds test at $k=2$ and at $10 \%$ significance level is $(3.17,4.14)$. Based on the results in Table 2, only Equation (3) rejected $H_{0}$ at $10 \%$ significance level. Equations (1) and (2) failed to reject $H_{0}$ at $10 \%$ significance level. As a 
result, it means that the long-run cointegration only happen when HEALTH is the dependent variable. It means that there was a long-run Granger causality from independent to dependent variables.

After the bounds test found a long-run relationship, the ARDL model is estimated with the following equation:

$$
\begin{aligned}
& \left(1-\emptyset_{1} L \ldots-\emptyset_{\mathrm{p}} L^{p}\right) \text { HEALTH } \\
& \qquad \quad \beta_{\mathrm{o}}+\left(1-\beta_{1} L \ldots-\beta_{\mathrm{r}} L^{T}\right) G D P_{\mathrm{t}}+\left(1-\alpha_{1} L \ldots-\alpha_{q} L^{q}\right) \text { TOURISM }_{\mathrm{t}}+\varepsilon_{\mathrm{t}}
\end{aligned}
$$

All the values of $p, q$, and $r$ are selected based on Schwarz information criterion (SIC). The estimated output of Equation (5) is shown as below:

$$
\text { HEALTH }_{t}=-\begin{gathered}
3.2622 \\
(0.0011)
\end{gathered} \quad \begin{gathered}
1.5649 \text { GDP }_{t} \\
(0.0337)
\end{gathered} \quad \begin{gathered}
0.2358 \text { TOURISM }_{t} \\
\text { (0.0398) }
\end{gathered}
$$

From the long-run model in Equation (5), GDP and TOURISM are significant at the 5\% level, respectively. Next the Granger causality test will be employed based on the following models:

$$
\begin{aligned}
& \Delta G D P_{\mathrm{t}}=d_{0}+\sum_{i=1}^{q} d_{G i} \Delta G D P_{\mathrm{t}-\mathrm{i}}+\sum_{i=1}^{q} a_{\tau i} \Delta \text { TOURISM }_{\mathrm{t}-\mathrm{i}}+\sum_{i=1}^{q} d_{H i} \Delta \text { HEALTH } H_{\mathrm{t}-\mathrm{i}}+\mu_{1 \mathrm{t}} \\
& \Delta \text { TOURISM }_{\mathrm{t}}=e_{0}+\sum_{\mathrm{i}=1}^{\mathrm{q}} b_{T i} \Delta \text { TOURISM }_{\mathrm{t}-\mathrm{i}}+\sum_{\mathrm{i}=1}^{q} \mathrm{e}_{G \mathrm{i}} \Delta G D P_{\mathrm{t}-\mathrm{i}}+\sum_{\mathrm{i}=1}^{q} e_{\mathrm{Hi}} \Delta \text { HEALTH }_{\mathrm{t}-\mathrm{i}}+\mu_{2 \mathrm{t}} \\
& \Delta H E A L T H_{\mathrm{t}}=h_{0}\left\|\sum_{i=1}^{q} h_{H 1} \Delta H E A L T H_{\mathrm{t}-1}\right\| \sum_{i=1}^{q} h_{G 1} \Delta C D P_{\mathrm{t}-1} \| \sum_{i=1}^{q} h_{T 1} \Delta \text { OUVRISM }_{\mathrm{t}-1} \mid h_{1} E C T_{\mathrm{t}-1} \\
& +\mu_{3 \mathrm{r}}
\end{aligned}
$$

\begin{tabular}{|c|c|c|c|c|c|}
\hline \multirow{3}{*}{ Equation } & \multirow{3}{*}{$\begin{array}{l}\text { Dependent } \\
\text { Variable }\end{array}$} & \multicolumn{3}{|c|}{ Independent Variables } & \multirow{3}{*}{$\frac{t \text {-test }}{E C T_{\mathrm{t}-1}{ }^{\mathrm{a}}}$} \\
\hline & & \multicolumn{3}{|c|}{$F$ test } & \\
\hline & & $\triangle G D P$ & $\Delta$ TOURISM & $\triangle H E A L T H$ & \\
\hline (6) & $\triangle G D P$ & - & 1.2053 & 0.1924 & - \\
\hline (7) & $\triangle T O U R I S M$ & 0.0618 & - & 2.5270 & - \\
\hline (8) & $\triangle H E A L T H$ & 1.6053 & 0.9390 & - & $\begin{array}{r}-0.9581^{* *} \\
(0.0326)\end{array}$ \\
\hline
\end{tabular}

Since only long-run cointegration happens when $H E A L T H$ is the dependent variable, the $E C T_{t-1}$ is added in the Granger causality test only in Equation (8). The $E C T_{t-1}$ is the lagged error correction term. The values of $q$ for Equations (6), (7), and (8) are also started from 1 and increased until they meet the null hypothesis of no autocorrelation by using the Breusch-Godfrey Lagrange multiplier test up to lag order 2 at $5 \%$ significance level.

Table 3. Results of Granger Causality

** Significant at $5 \%$ level

${ }^{a}$ Estimated value of $h 1$ is report in this column.

From Table 3, Equation (8) shows that $h_{1}=-0.9581$ and $-1<h_{1}<0$ at $5 \%$ significant level. It means that a short-run change in the independent variables had an effect on the dependent variable in the Equation (8) model in the long-run equilibrium. 
On the other hand, Equations (6), (7), and (8) failed to reject $H_{0}$ at 5\% significance level. It means that there was no short-run Granger causality from independent variables to dependent variables in Equations (6), (7), and (8).

Based on the results from bound and Granger causality tests, the short- and long-run Granger causality of this study are shown in Figure 1.

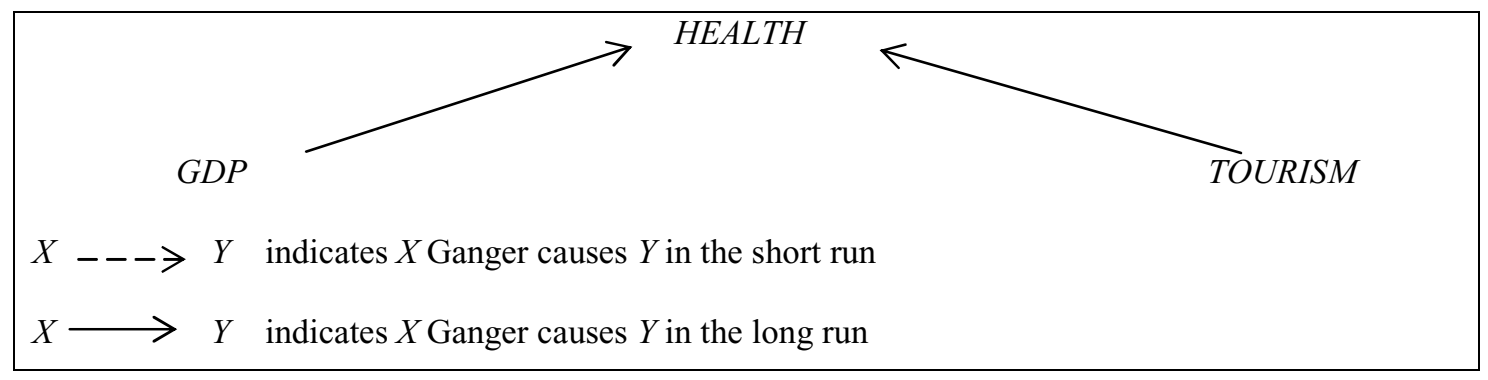

Figure 1. Summary of short- and long-run Ganger causality in Malaysia.

\section{Conclusion}

In the long-run model, it was found that income has a positive impact on the health sector. It is true because when citizens' income increases, the government will increase health care spending to fulfill the increase of demand for health care services.

But tourist arrivals have a negative impact on government health care spending. According to Pocock and Phua [6], the Malaysian government has a policy on the private sector, which will play a role in developing the health care sector of Malaysia. As more tourists visit Malaysia for health care services, the government will reduce its role, and the private sector will play a role to increase quality of health care services.

Results of this study are in contrast with the study done by Lee and Hung [11], which was based on data from Singapore. In this study, Malaysia has a big difference when compared with the study done by Lee and Hung [11]. The main reason is that Malaysia is a developing country, but Singapore is a developed country, according to the World Bank (2013). Based on this difference of national income between Malaysia and Singapore, economic performances also will be different.

In this study, there are two reasons to support the above relationships. First is the increase in life expectancy at birth for Malaysia citizens. As the income of the Malaysia citizens is increased, health care expenses also will increase. Second, it will increase life expectancy at birth of Malaysia citizens. According to the World Bank (2014), the life expectancy at birth of Malaysia citizens at year 2011 is 74.7.

Malaysia also has been conducting the Visit Malaysia Year (VMY) program since 1990. The aim of the program is to promote Malaysia to tourists around the world. At the same time, this program also can help to increase Malaysia GDP. In VMY 2014, with the theme "Celebrating 1Malaysia Truly Asia," Malaysia targeted to have RM 168 billion tourism receipts and 36 million people in tourism arrivals by year 2020 [15].

Development from economic and tourism sectors should be maintained. With this development, the health care sector also will be increased. The health care sector plays an important role in the development of Malaysia. With a good level of health care services, Malaysian life expectancy will be increased. With better health and long-life citizens, Malaysia can move faster to become a highincome nation before year 2020 .

In conclusion, everyone in Malaysia plays an important role in ensuring that Malaysia achieves high-income nation status during the year 2020. Malaysian has been putting its hands together irrespective of the races to raise the development of the tourism and health care sectors for the growth of the Malaysian economy. 


\section{References}

1. The Malaysia Healthcare Travel Council.(2013). Malaysia Your Healthcare Destination. Retrieved on November 11, 2013 from http://www.medicaltourism.com.my/en/malaysia-yourhealthcare.aspx.

2. The Malaysia Healthcare Travel Council.(2013). Overall healthcare travelers 20072012.Retrievedon November 11, 2013 from http://www.mhtc.org.my/en/statistics.aspx.

3. V. A Crooks, P.Kingsbury, J.Snyder and R.Johnston. What is known about the patient's experience of medical tourism? A scoping review. BMC Heal. Ser. Res, 10, 266 (2010)

4. R. Johnston, V.A.Crooks, J.Snyder and P. Kingsbury. What is known about the effects of medical tourism in destination and departure countries? A scoping review. Int. Jor. for Eq. in Heal, 9,24, 9-24 (2010)

5. M. Ormond. Shifting subjects of health-care: placing 'medical tourism' in the context of Malaysia domestic health-care reform. Asi. Pac. View, 52,3, 247-259 (2011)

6. N. S. Pocock, and K.H.Phua. Medical tourism and policy implications for health systems: a conceptual framework from a comparative study of Thailand, Singapore and Malaysia. Globaliz. and Heal., 7,12, 336-357 (2011)

7. P.S. Cook. What is health and medical tourism? Humanities Research Program. Queens Uni of Tech. Pp. 13 (2008)

8. A. Hundt. Impact of tourism development on the economy and health of the third world nations. J. of Trav. Medi., 3,2, 107-112 (1996)

9. J. F. Outreville. Foreign direct investment in the health care sector and most-favoured locations in developing countries. The Eur. Jor. of Heal. Econ., 8,4, 305-312 (2007)

10. R. Durbarry, (2004). Tourism and economic growth: the case of Mauritius. Touri. Econ., 10,4, 389-401 (2004)

11. C. G. Lee, and W.T.Hung.Tourism, health and income in Singapore. Int. J. of Tour. Res., 12, 355-359 (2010)

12. C. F. Tang. Temporal Granger Causality and the dynamics relationship between real tourism receipts, real income and real exchange rates in Malaysia. Int. J. of Tour. Res., 15(13), 272-284 (2012)

13. M. Ramesh, and I.Holliday. The health care miracle in East and Southeast Asia: Activiest state provision in Hong Kong, Malaysia and Singapore. J. of Soc. Polic., 30: 637-651 (2001)

14. M. H. Pesaran, Y.Shin, and R.J.Smith. Bounds testing approaches to the analysis of level relationships. J. of App. Econometrics, 16, 289-326 (2001)

15. Ministry of Tourism Malaysia.(2014). History of Visit Malaysia Year. Retrieved on April 3, 2014 from http://www.vmy2014.com/about-vmy2014/history-of-visit-malaysia-year. 